\title{
Benzo-benzothiopyranoquinoline Derivatives of Possible Antiparasitic Activity
}

\author{
A. Zayed* and J. Metri \\ National Research Centre Dokki, Cairo, Egypt \\ Z. Naturforsch. 33 b, 554-556 (1978); received January 5, 1978
}

Benzo-benzothiopyranoquinoline, Benzoquinoline, Synthesis, Reactions, Antiparasitic Activity

For possible antiparasitic activity, benzo-benzothiopyranoquinoline-6-malonaldehyde was synthesized and condensed with hydrazine hydrate, phenylhydrazine and/or 0-phenylenediamine. This afforded pyrazole, phenylpyrazole and diazepin derivatives respectively.

It has been found that a number of benzoquinolines possess antimalarial activity [1]. These type of compounds have the naphthalene moiety, which may undergo biological oxidation to the corressponding quinones $[2,3]$. It was reported that some benzoquinones and naphthoquinones are potential bioreductive alkylating agents [4-6]. Also, naphthoquinones can highly reduce the rate of glycolysis in some parasites [7].

This led us to study the synthesis of benzo[h]quinolines incorporating benzothiopyrano moiety, analogeous to azamiracils [8-12], which are expected to possess biological activity.

Condensation of 1-naphthylamine with acetoacetic ester at room temperature, followed by cyclization in preheated mineral oil, gave 4hydroxy-2-methylbenzo[h]quinoline (1). This upon treatment with phosphorus oxychloride, yielded the 4-chloro derivative (2). Reaction of 2 with thiosalicylic acid in presence of $\mathrm{C}_{2} \mathrm{H}_{5} \mathrm{O} \mathrm{Na}$ or alcoholic $\mathrm{NaO} \mathrm{H}$ soln. afforded 2-methyl-4-(benzo[h]quinolinoyl)-2-carboxyphenylsulphide (4). Compound 4 was also prepared by reaction of 2 with thiourea [13], followed by hydrolysis with $\mathrm{NaOH}$ soln. to give 4-mercapto derivative (3), which was finally condensed with $o$-chlorobenzoic acid.

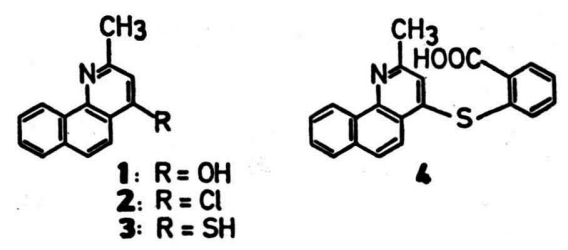

Cyclization of 4 was affected with polyphosphoric acid to give 6-methyl-7-H-benzo[ $h][1]$ benzothiopyrano[3,2,C]quinolin-7-one (5). The methyl group

Requests for reprints should be send to Dr. A. Zayed, National Research Centre Dokki, Cairo, Egypt. in 5 was subjected to formylation reaction with POCL $_{3}-\mathrm{DMF}$, followed by alkaline hydrolysis with $5 \% \mathrm{KOH}$ soln., which gave 7-oxo-7 $H$-benzo[h][l]benzothiopyrano $[3,2, C]$ quinoline-6-malonaldehyde (6).
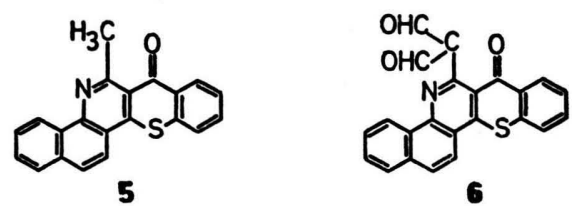

The chemotherapeutic interest of pyrazole, suggested its introduction. This was acheived by reaction of 6 with hydrazine hydrate and/or phenylhydrazine, to yield 6-(pyrazol-4-yl)-7 $H$-benzo[ $h][1]$ benzothiopyrano[3,2,C]quinolin-7-one $(7 \mathrm{a})$ and 6 [1-(phenyl)pyrazol-4-yl]-7 $H$-benzo[ $h][1]$ benzothiopyrano $[3,2, C]$ quinolin-7-one $(7 \mathrm{~b})$, respectively. While, the reaction of 6 with $o$-phenylenediamine, afforded 6-(3H-1,5-benzodiazepin-3-yl)-7 $H$-benzo$[h][1]$ benzothiopyrano[3,2,C]quinolin-7-one (8) in $56 \%$ yield.
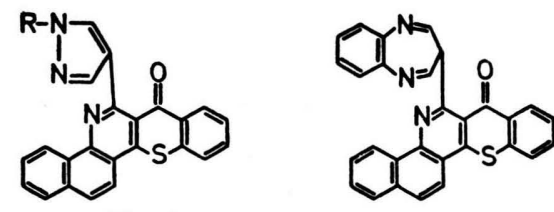

7a: $\mathrm{R}=\mathrm{H}$

7b: $\mathrm{R}=\mathrm{C}_{6} \mathrm{H}_{5}$

Experimental

Melting points are uncorrected, and were taken on Gallenkamp electric melting point apparatus and Boetius melting point microscope.

Infrared spectra were performed on a Carl Zeiss

Infracord spectrophotometer model "UR 10" using $\mathrm{KBr}$.

NMR spectra were obtained in $\mathrm{CF}_{3} \mathrm{COOH}$ with a Varian Associates model "A-60" spectrometer.

Microanalysis were performed by the Microanalytical Laboratory, National Research Centre, Cairo, Egypt. 


\section{4-Hydroxy-2-methylbenzo[h]quinoline (1)}

A mixture of 1-naphthylamine (14.3 g) and ethyl acetoacetate (13 g) containing 2 drops of conc. HCL was kept at room temperature overnight.

The thick, red oil was taken up in ether, and the ethereal extract was washed successively with water, dil. $\mathrm{NaOH}$ soln. and again with water. The solvent was distilled after drying over $\mathrm{Na}_{2} \mathrm{SO}_{4}$ anhydrous to leave the intermediate naphthylamino acrylate. This was poured gradually onto paraffin oil preheated to $270^{\circ} \mathrm{C}$. On cooling, 1 was obtained, m.p. $>300{ }^{\circ} \mathrm{C}[14]$.

\section{4-Chloro-2-methylbenzo[h]quinoline (2)}

Compound $1(10 \mathrm{~g})$ was refluxed with an excess of $\mathrm{POCL}_{3}$ for $6 \mathrm{~h}$. The reaction mixture was poured on crushed ice and filtered. The cold filtrate was basified with amnonia soln. to give 2 as white crystals, m.p. 91-92 ${ }^{\circ} \mathrm{C}$ (lit. [14], m.p. $93^{\circ} \mathrm{C}$ ).

\section{4-Mercapto-2-methylbenzo[h]quinoline (3)}

To a solution of thiourea $(\mathbf{l g})$ in absolute ethanol $(15 \mathrm{ml}) 2$ was added $(3 \mathrm{~g})$ dissolved in least amount of ethanol. The reaction mixture was refluxed for 30 min. After cooling the thioronium salt was precipitated, filtered off, and hydrolyzed by refluxing with $30 \% \mathrm{KOH}(20 \mathrm{ml})$ for $5 \mathrm{~h}$. The reaction mixture was filtered, and the cold filtrate was acidified with acetic acid to give $2 \mathrm{~g}$ of $3, \mathrm{~m} . \mathrm{p}$. 201-203 ${ }^{\circ} \mathrm{C}$.

\section{$\mathrm{C}_{14} \mathrm{H}_{11} \mathrm{NS}$ (225.23) \\ Calcd C 74.66 H 4.92 S 14.12, \\ Found C 74.16 H 4.52 S 13.94 .}

\section{2-Methyl-4-(benzo[h]quinolinoyl)- $\overline{2}$-carboxyphenyl-} sulphide (4)

\section{Method $A$}

A mixture of $2(4.69 \mathrm{~g} ; 0.02$ mole $)$ and thiosalicylic acid ( $3.12 \mathrm{~g} ; 0.02$ mole) was added to an alcoholic soln. of $\mathrm{C}_{2} \mathrm{H}_{5} \mathrm{O} \mathrm{Na}$, that prepared from $\mathrm{Na}$ $(\mathrm{g})$ and absolute ethanol $(40 \mathrm{ml})$. The reaction mixture was refluxed for $12 \mathrm{~h}$, then the alcohol was concentrated and acidified with dil. acetic acid. The precipitated product was isolated, washed with water and dried. Recrystallization from aqueous ethanol gave $66 \%$ yield of 4, m.p. $212-213{ }^{\circ} \mathrm{C}$.

IR: $1690(-\mathrm{COOH})$ and $700 \mathrm{~cm}^{-1}(-\mathrm{S}-)$.

$\begin{array}{ccccc}\mathrm{C}_{21} \mathrm{H}_{14} \mathrm{NS}_{2} \mathrm{O} & (344.34) & & & \\ \text { Calcd } & \mathrm{C} \mathrm{73.25} & \mathrm{H} 4.09 & \mathrm{~N} 4.07 & \mathrm{~S} \mathrm{9.30}, \\ \text { Found } & \mathrm{C} \mathrm{73.65} & \mathrm{H} \mathrm{4.49} & \mathrm{N} \mathrm{3.99} & \mathrm{S} 9.70 .\end{array}$

\section{Method $B$}

A mixture of $2(5 \mathrm{~g})$ and thiosalicylic acid (3.5 g) in ethanol $(100 \mathrm{ml})$ was refluxed, whereby $40 \%$ $\mathrm{NaOH}$ soln. $(5 \mathrm{ml})$ was added dropwise. Refluxing was continued for $8 \mathrm{~h}$. The product was isolated as previously described to give 4 in $71 \%$ yield, m.p. 213-214 ${ }^{\circ} \mathrm{C}$.

\section{Method $C$}

To a soln. of $\mathrm{C}_{2} \mathrm{H}_{5} \mathrm{O} \mathrm{Na}(0.4 \mathrm{~g}$ of $\mathrm{Na}$ in $20 \mathrm{ml}$ absolute ethanol) was added a mixture of $3(1.5 \mathrm{~g}$; $0.003 \mathrm{~mole})$ and $o$-chlorobenzoic acid (1.04 g; 0.003 mole). The reaction mixture was refluxed for $10 \mathrm{~h}$ and the product was worked up as mentioned above, $68 \%$ yield. The three methods gave the same product (m.p. and admixed m.p.).

\section{6-Methyl-7H-benzo[h][l]benzothiopyrano[3,2,C]- quinolin-7-one (5)}

Polyphosphoric acid $(20 \mathrm{~g})$ was heated to $170^{\circ} \mathrm{C}$, then 4 (3 g) was added portionwise by gentle shaking. After $4 \mathrm{~h}$ the mixture was cooled and poured onto ice-water. The obtained precipitate was collected, washed thoroughly with boiling ammonium hydroxide soln., then with water and dried. It gave $72 \%$ yield of 5, m.p. $248-250{ }^{\circ} \mathrm{C}$ (chloroform).

IR: $1640(-\mathrm{C}=0) ; 1590(-\mathrm{C}=\mathrm{N})$ and $750 \mathrm{~cm}^{-1}(-\mathrm{S}-)$.

$\mathrm{C}_{21} \mathrm{H}_{13} \mathrm{NSO}$ (327.39)

$\begin{array}{llllll}\text { Calcd } & \text { C 77.04 } & \text { H } 4.00 & \text { N 4.28 } & \text { S } & 9.80 \text {, }\end{array}$

Found $\quad$ C 77.13 H 4.05 N 4.52 $\quad$ S 10.30 .

\section{7-Oxo-7 H-benzo[h] [l]benzothiopyrano [3,2,C]- \\ quinoline-6-malonaldehyde (6)}

Freshly distilled $\mathrm{POCL}_{3}(1 \mathrm{ml})$ was added dropwise with stirring to dimethylformamide $(3 \mathrm{ml})$ at $0-5{ }^{\circ} \mathrm{C}$. A soln. of $5(1.2 \mathrm{~g} ; 0.003 \mathrm{~mole})$ in dimethylformamide $(2 \mathrm{ml})$ was added dropwise at $5-10^{\circ} \mathrm{C}$, and the reaction mixture was allowed to stand at room temperature for $30 \mathrm{~min}$. It was then heated at $70{ }^{\circ} \mathrm{C}$ for about $6 \mathrm{~h}$, and poured onto Crushed ice. The aqueous soln. was treated with $5 \% \mathrm{KOH}$ soln., which furnished $1 \mathrm{~g}(72 \%$ yield) of 6 , it showed m.p. $305-306{ }^{\circ} \mathrm{C}$ from chloroform.

IR: $1660 \mathrm{~cm}^{-1}(-\mathrm{CHO})$.

NMR ( $\left.\mathrm{CF}_{3} \mathrm{COOH}\right): \mathrm{t} 8.65$ (methine protons, triplet); t 7.10 and t 6.52 aldehydic protons, doublet) and t 2.2 (aromatic protons, complex pattern).

$\mathrm{C}_{23} \mathrm{H}_{13} \mathrm{NO}_{3} \mathrm{~S}$ (383.35)

$\begin{array}{lllll}\text { Calcd } & \text { C 72.06 } & \text { H 3.40 } & \text { N 3.60 } & \text { S 8.30, } \\ \text { Found } & \text { C 72.45 } & \text { H 3.75 } & \text { N 3.54 } & \text { S 8.76. }\end{array}$

\section{6-(Pyrazol-4-yl)-7 H-benzo[h][l]benzothiopyrano-} [3,2,C]quinolin-7-one (7 a)

A mixture of $6(0.8 \mathrm{~g})$ and hydrazine hydrate $(0.17 \mathrm{ml})$ in ethanol $(20 \mathrm{ml})$ was refluxed for $10 \mathrm{~h}$. The reaction mixture was cooled, and the separated solid was isolated, crystallized from dimethylformamide, m.p. $345-348^{\circ} \mathrm{C}(81 \%$ yield $)$.

IR: $3160 \mathrm{~cm}^{-1}$ (-NH Stretching).

$\begin{array}{crrrr}\mathrm{C}_{23} \mathrm{H}_{13} \mathrm{~N}_{3} \mathrm{OS} & (279.37) & & \\ \text { Calcd } & \mathrm{C} 72.82 & \mathrm{H} 3.43 & \mathrm{~N} 11.08, \\ \text { Found } & \mathrm{C} 72.32 & \mathrm{H} 3.69 & \mathrm{~N} 10.90 .\end{array}$


6-[1-(Phenyl)pyrazol-4-yl]-7 H-benzo[h][l]benzothiopyrano [3,2,C]quinolin-7-one (7b)

Compound $6(0.8 \mathrm{~g})$ in ethanol $(15 \mathrm{ml})$ was heated under reflux for $8 \mathrm{~h}$, with phenylhydrazine $(0.25 \mathrm{ml})$. After cooling the obtained precipitate was crystallized from chloroform to furnish $83 \%$ yield of $7 \mathbf{b}$, m.p. 274-276 ${ }^{\circ} \mathrm{C}$.

$\mathrm{C}_{29} \mathrm{H}_{17} \mathrm{~N}_{3} \mathrm{OS}$ (455.46)

Calcd C 76.48

Found $\mathrm{C} 76.60$
6-(3H-1,5-Benzodiazepin-3-yl)-7H-benzo[h [ [l]benzothiopyrano [3,2,C]quinolin-7-one (8)

A mixture of $6(0.8 \mathrm{~g})$ and $o$-phenylenediamine $(0.23 \mathrm{~g})$ in ethanol $(20 \mathrm{ml})$ was heated under reflux for $8 \mathrm{~h}$ working up as described above produced 8 in $56 \%$ yield, m.p. $>350{ }^{\circ} \mathrm{C}$ from dimethylformamide.

$\mathrm{C}^{29 H 16 \mathrm{~N}_{3} \mathrm{SO}}(\mathbf{4 5 4 . 4 5 )}$

Calcd C 76.65 H 3.52 N 9.40 S 7.04, Found $\quad$ C 76.30 $\quad$ H $3.62 \quad$ N 9.00 $\quad$ S 7.54.
[1] P. William, J. Utermohlen, and C. S. Hamilton, J. Am. Chem. Soc. 63, 156 (194I).

[2] E. Grandmougin and O. Michel, Chem. Ber. 25, 972, (1892).

[3] R. T. Arnold and H. E. Zaugg, J. Am. Chem. Soc. 63, 1317 (194I).

[4] A. J. Lin, L. A. Cosby, C. W. Shansky, and A. C. Sartorelli, J. Med. Chem. 15, 1247 (1972).

[5] A. C. Sartorelli, A. J. Lin, R. S. Pardini, L. A. Cosby, B. J. Lillis, C. W. Shansky, and A. C. Sartorelli, ibid. 16, 1268 (1973).

[6] A. J. Lin and A. C. Sartorelli, ibid. 19, 1336 (I976).

[7] E. Bueding and L. Peters, J. Pharmacol. 101, 210 (1951).
[8] M. C. Chiiang and W. H. Hartung, J. Org. Chem. 10, 2 I (1945).

[9] C. H. Browning, J. B. Elling, and R. Gulbransen, Proc. Roy. Soc. 110 B, 372 (1932).

[10] R. Gonnert, Bull. Org. Mond. Sante, Bull. World. Hith. Org. 25, 702 (1961).

[11] N. J. Leonard, H. F. Herbrandson, and E. M. Heyningen, J. Am. Chem. Soc. 68, 1279 (1946).

[12] D. M. Bailey, S, Archer, D. Wood, D. Rosi, and A. Yarinsky, J. Med. Chem. 13, 598 (1970).

[13] A. G. Renfrew, J. Am. Chem. Soc. 68, 1433 (I946).

[14] G. S. Charles, V. H. Kalvoi, N. M. Kottiazath, and L. S. John, J. Chem. Soc. 1926, 2247. 